\title{
Análise das percepções de estudantes do ensino médio sobre o filme: "O Céu de Outubro"
}

\author{
Daiane Thais Ludvig \\ Daya.ludvig@hotmail.com \\ orcid.org/0000-0001-5386-8039 \\ Universidade Estadual do Oeste do \\ Paraná (Unioeste), Toledo, Paraná, Brasil \\ Bruna Patereck \\ brunaa.patereck@hotmail.com \\ orcid.org/0000-0003-2777-5925 \\ Universidade Estadual do Oeste do \\ Paraná (Unioeste), Toledo, Paraná, Brasil

\section{Caroline Fortuna} \\ carolinefortunacf@gmail.com \\ orcid.org/0000-0003-3666-7870 \\ Paraná (Unioeste), Toledo, Paraná, Brasil

\section{Claudia Regina Machado} \\ Kliemann \\ claudiakliemann@yahoo.com.br \\ orcid.org/0000-0002-7903-1373 \\ Universidade Estadual do Oeste do \\ Paraná (Unioeste), Toledo, Paraná, Brasil \\ Daiany Helscher da Silva \\ dai anysilva@hotmail.com \\ orcid.org/0000-0001-7295-1006 \\ Universidade Estadual do Oeste do
Paraná (Unioeste), Toledo, Paraná, Brasil
}

\section{RESUMO}

O presente artigo apresenta uma atividade realizada com estudantes do $3^{\circ}$ Ano do Ensino Médio sobre o filme "O Céu de Outubro". Esse filme retrata o empenho de estudantes de uma pequena cidade que se dedicam na construção de um foguete, a fim de serem selecionados para a feira de ciências. Na atividade, os estudantes analisam criticamente aspectos/contextos abordados no enredo do filme. $\mathrm{O}$ trabalho realizado teve como objetivo propor aos estudantes uma análise crítica dos contextos familiares, políticos, históricos, sociais e a atividade científica voltada para a feira de ciências apresentados no filme, utilizando a proposta apresentada no artigo de Eduardo Fleury Mortimer e de Phil Scott, que propõe uma ferramenta para analisar as intervenções e as intenções no discurso do professor em sala de aula. O método de análise forneceu subsídios para inferir que o bom andamento da discussão do filme depende das intervenções do professor, o qual medeia o discurso para a intenção e o foco desejado, explorando a visão dos estudantes sobre os contextos apontados no filme.

PALAVRAS-ChAVE: Ensino de Química. Atividade discursiva. Percepções. Intervenções. Filmes. Feira de Ciências. 


\section{INTRODUÇÃO}

Fazer os alunos assistirem a um filme como estratégia de ensino é uma atividade didática que pode ser relacionada com diversas áreas do conhecimento, sendo uma delas a área de Ciências. Dessa forma, o professor pode utilizar essa ferramenta para contemplar a sua aula, pois, além de ser uma metodologia diferenciada, também é atrativa aos olhos dos estudantes e pode estimular a reflexão crítica do que está sendo tratado no filme sobre as realidades humanas.

A escola se caracteriza por ser um espaço de conhecimento formal, mas não é apenas isso, pois os estudantes possuem experiências anteriores e externas ao espaço escolar. Dessa forma, o ambiente escolar se torna um "[...] espaço do confronto e diálogo entre os conhecimentos sistematizados e os conhecimentos do cotidiano popular" (PARANÁ, 2008, p. 23), provenientes inclusive de filmes, por exemplo. A escola é, então, certamente um espaço em que devem ser consideradas as percepções dos estudantes.

\section{O FILME EM SALA DE AULA}

Ensinar não é uma tarefa fácil, pois exige do professor determinação e criatividade na busca de variadas metodologias de ensino para que esse objetivo seja realmente alcançado. Nesse sentido, o cinema/filme pode ser utilizado, não somente como forma de entretenimento, mas como uma ferramenta educativa relevante para auxiliar no processo de ensino-aprendizagem (COELHO; VIANA, 2010). Conforme destaca Cipolini (2008):

[...] o filme pode ser utilizado como instrumental didático ilustrando conteúdos, principalmente referentes a fatos históricos; como motivador, na introdução de temas psicológicos, filosóficos e políticos, estimulando o debate; ou como um objeto de conhecimento, na medida em que é uma forma de reconstrução da realidade (CIPOLINI, 2008, p. 19).

Podemos observar que os fatos históricos e os acontecimentos marcantes para a sociedade são, diversas vezes, temas retratados em filmes, motivo pelo qual "[...] muito da percepção que temos da história da humanidade talvez esteja irremediavelmente marcada pelo contato que temos/tivemos com as imagens cinematográficas" (DUARTE, 2002, p. 18). Referentemente a isso, é essencial ressaltar que:

O significado cultural de um filme (ou de um conjunto deles) é sempre constituído no contexto em que ele é visto e/ou produzido. Filmes não são eventos culturais autônomos, é sempre a partir dos mitos, crenças, valores e práticas sociais das diferentes culturas que narrativas orais, escritas ou audiovisuais ganham sentido (DUARTE, 2002, p. 51-52).

Assim, a utilização do filme em sala de aula deve superar a mera ilustração de algum fenômeno ou acontecimento. É essencial que seja buscado o significado do filme, caracterizando o contexto da época de sua produção, contextualizando com o cotidiano dos estudantes.

Utilizar filmes durante as aulas é um método de ensino considerado, por 
significados, pois "O cinema possibilita o encontro entre pessoas, amplia o mundo de cada um, mostra na tela o que é familiar e o que é desconhecido e estimula o aprender. [...] aguça a percepção e torna mais ágil o raciocínio [...]" (ALENCAR, 2007 , p. 137). Assim, quando utilizados em sala de aula, os filmes podem auxiliar no processo de ensino-aprendizagem, aproximando o estudante do conteúdo em estudo, proporcionando a articulação entre o filme e a temática estudada.

Podemos pontuar aspectos que o constituem esse tipo de estudo positivamente, pois a utilização do filme em sala de aula pode ser considerada uma ferramenta de ensino relevante, que auxilia na assimilação da temática em estudo. Além disso, provoca um maior impacto inicial em comparação com a simples escrita sobre a temática, e também incentiva o envolvimento, pois permite que o estudante relacione as cenas do filme com o seu cotidiano. Isso ocorre, de acordo com Viana (2002), pois:

\footnotetext{
O adequado equilíbrio entre as palavras e as imagens facilita os processos de desenvolvimento do pensamento em geral e, em particular, no processo de ensino/aprendizagem. É por isso que se assinala que sem sensações, percepções e representações não há desenvolvimento do pensamento; daí ser importante, sempre que possível, além das palavras, usar representações visuais (VIANA, 2002, p. 77).
}

Dessa forma, o autor afirma que as crianças aprendem vendo filmes. Além disso, criam estímulos e interesse para lerem textos escritos, sendo que isso não acontece somente em crianças, mas também em jovens e em adultos. Assim, é relevante que o professor destaque, dos filmes, fragmentos que podem causar reflexões críticas e instigar o raciocínio dos estudantes. Dessa forma, o docente conduzirá a intermediação entre o filme e o conhecimento.

De acordo com Cipolini (2010), o filme pode auxiliar na estruturação de temáticas das aulas de Ciências e para disciplinas diversas e também pode dar alicerce à elaboração de inúmeras atividades, como, por exemplo, de uma feira de ciências. A partir do filme, os estudantes se baseiam em experiências vividas por personagens e as relacionam com as suas perspectivas, motivando-os a planejar novos projetos e a incorporarem as necessidades da sociedade. Por isso, é essencial ressaltar que o cinema exige do telespectador um olhar atento, pois pode ser influenciado por diversos fatores externos, como, por exemplo, o contexto social, econômico, familiar e cultural.

Assim, é possível perceber, entre os estudantes, como, individualmente, vão formando ideias diferentes sobre o filme.

\section{PERCEPÇÃO DOS ESTUDANTES SOBRE CIÊNCIA}

Atualmente o ensino de Ciências das escolas brasileiras ainda acontece, muitas vezes, de forma tradicional. Entretanto, muito tem sido questionado sobre esse formato de ensino e aprendizagem e, nos últimos tempos, tem aumentado o número das pesquisas com o intuito de suplantar esse modelo.

A chamada Alfabetização Científica passou a ser compreendida como essencial para a formação de uma educação cidadã, para o entendimento e a utilização dos conhecimentos científicos na própria vida do estudante e no seu convívio em sociedade (SASSERON; CARVALHO, 2011). Essa Alfabetização 
Científica apresenta-se então com o intuito de desenvolver um pensamento crítico sobre os contextos nos quais os estudantes estão inseridos, para que tenham a compreensão dos assuntos tratados e possam sobre eles assumir um posicionamento pautado em argumentos, o que acarreta uma percepção maior do mundo e das coisas que os cercam.

Tal percepção inclui analisar, compreender, buscar informações, criticar, argumentar sobre ciência e tecnologia. Isso não é nada mais que reproduzir em sala o que acontece cotidianamente em pequenas ações, relacionadas diretamente com a vida, com o futuro próximo, formar cidadãos críticos permitindo uma maior qualidade de vida.

Associados a isso, os estudos tradicionais sobre percepção da ciência são baseados em conhecer o grau de interesse pela informação científica em formas de percepções visuais, abandonando fatores que envolvem a mente.

Santaella (1998) comenta, em seu capítulo introdutório, que o século passado viu emergir diversas teorias de percepção, havendo foco sobre os aspectos visuais implicados. A autora nota que tão forte foi a prevalência do visual nos estudos que a relação com a mente foi de certa forma excluída.

No entanto, Cunha (2009) considera que a percepção é algo mais abrangente, e destaca que:

[...] não é uma mera detecção ou reação aos estímulos internos ou externos ao indivíduo. Ao contrário do ato de sentir, perceber é detectar, é interpretar sinais que têm origem externa ao sistema nervoso central [...] é uma elaboração em que o alicerce são as sensações, as memórias, as vivências, as experiências e as expectativas, sejam elas inatas ou adquiridas por meio da interação com o meio. Por isso, a percepção é um processo mental seletivo, ou seja, não percebemos tudo aquilo que chega aos nossos órgãos dos sentidos. O mundo exterior é oferecido a nós como um cardápio variado e, a partir de nosso modo de perceber, selecionamos eventos e situações deixando de fora os que não nos fazem sentido (CUNHA, 2009, p. 28).

Dessa forma, é possível afirmar que uma mesma situação pode ser percebida de maneiras diferentes por pessoas distintas, pois as percepções são subjetivas, formuladas individualmente e de acordo com as experiências vividas de cada um, conferindo-lhe um valor próprio. Assim, cada indivíduo, conforme a sua realidade, constrói os conhecimentos sobre as coisas.

\section{MÉTODO}

\section{CARACTERIZANDO A ATIVIDADE REALIZADA}

Neste estudo relatamos uma atividade desenvolvida em aulas de Química do Colégio Estadual Jardim Gisele, Toledo-PR. Foi elaborada por um grupo do PIBID, composto por acadêmicas do Curso de Química Licenciatura da Universidade Estadual do Oeste do Paraná, e desenvolvida com uma turma da 3a série, do Ensino Médio, composta por 17 estudantes com idade entre 16 e 17 anos. A atividade teve duração de três aulas e teve o objetivo de propor aos estudantes uma análise 
voltada para a feira de ciências, contextos esses abordados no filme "O Céu de Outubro", por meio de discussão.

A atividade baseou-se em um artigo escrito por Mortimer e Scott (2002) intitulado "Atividade discursiva nas salas de aula de Ciências: uma ferramenta sociocultural para analisar e planejar o ensino". Esse artigo propõe uma ferramenta analítica sociocultural para analisar tanto no que se refere aos aspectos do discurso do professor como em relação às interações professor/aluno, que resultam na construção de significado em aulas de Ciências.

Sabendo da necessidade de se tornar visíveis as práticas discursivas em sala de aula, os autores Mortimer e Scott (2002), em um de seus artigos, apresentam mecanismos para a análise das interações e para a produção de conhecimentos científicos significativos. Segundo os autores, a atividade discursiva é essencial para as diversas ações diárias desempenhadas pelos professores em sala de aula.

A análise discursiva proposta por Mortimer e Scott (2002) se focaliza no papel do professor e apresenta cinco aspectos de análise que se inter-relacionam, agrupadas de acordo com os focos do ensino, a abordagem e as ações, conforme apresentado no Quadro 1:

Quadro 1: Ferramenta de Análise das Interações e Produção de Significados em Sala de Aula de Ciências

Aspectos de Análise

\begin{tabular}{c|c}
\hline i. Focos de ensino & $\begin{array}{c}\text { 1. Intenções do professor } \\
\text { 2. Conteúdo }\end{array}$ \\
\hline ii. Abordagem & 3. Abordagem comunicativa \\
\hline iii. Ações & $\begin{array}{c}\text { 4. Padrões de interação } \\
\text { 5. Intervenções do professor }\end{array}$ \\
\hline
\end{tabular}

Fonte: Mortimer e Scott (2002).

$\mathrm{Na}$ atividade realizada, analisamos somente um aspecto dos focos de ensino, qual seja, as intenções do professor. Mortimer e Scoot (2002) consideram que o ensino de Ciências produz um tipo de "performance pública" na sala de aula, atividade em relação à qual cabe ao professor planejar, apresentar e dirigir as etapas nas aulas de Ciências, sempre com o objetivo de desenvolver a "estória científica" no plano social da sala de aula. O desenvolvimento desse roteiro é uma das intenções do professor.

Entre as intenções identificadas pelos autores estão: criando um problema, explorando a visão dos estudantes, introduzindo e desenvolvendo a "estória científica", guiando os estudantes no trabalho com as ideias científicas e dando suporte ao processo de internalização, guiando os estudantes na expansão do uso das ideias científicas e na expansão de seu uso, transferindo progressivamente para eles o controle e responsabilidade por esse uso e mantendo a narrativa, sustentando o desenvolvimento da "estória científica".

\section{O FILME “O CÉU DE OUTUBRO”}

No final dos anos 1950, o adolescente Homer Hickam vive na cidade de Coalwood, oeste da Virgínia, onde a mineração é a maior empregadora local. O 
filme começa contando sobre a "corrida espacial" entre os Estados Unidos e a Rússia, quando, em 1957, os russos lançaram ao espaço, o Sputnik. O fato inédito foi o estopim para Homer começar a sonhar em construir o seu próprio foguete. Logo ele convence seus amigos a participarem da feira de ciências e, com o apoio da sua professora de Ciências, dão início ao projeto.

Na cidade, o destino da maioria dos jovens era o trabalho na mina e somente aqueles que se destacavam nos esportes conseguiam uma bolsa de estudos em alguma universidade. Com pouca aptidão para o esporte, mas com a intenção de fugir do destino de minerador, Homer buscou em uma feira de ciências o caminho para a faculdade.

Mesmo após inúmeras tentativas frustradas na construção e lançamento do foguete, o grupo de meninos não desistiu, venceram a feira de ciências do colégio e puderam participar da Feira Nacional de Ciências, a qual ofertou bolsas de estudos em universidades para os ganhadores. Homer participou como representante do grupo e foi destaque na feira, sendo seu vencedor.

\section{A ESTRATÉGIA DE ENSINO}

A realização da atividade, da qual resultou a elaboração deste trabalho, ocorreu nas seguintes etapas: a pesquisa teórica, o desenvolvimento da atividade, que inclui a coleta de dados, e a análise dos resultados obtidos.

Primeiramente, foi elaborado um questionário em escala Likert, considerando os contextos retratados no filme em estudo, para que as questões fossem respondidas pelos estudantes com base nos seus conhecimentos prévios, ou seja, a partir das percepções que eles tinham sobre os contextos familiares, políticos, históricos, sociais e a atividade científica voltada para a feira de ciências, contextos abordados no filme "O Céu de Outubro".

Posteriormente, direcionamos os estudantes para identificarem os seguintes contextos: familiar e cultural; social, econômico e político; escolar e relacionado à atividade científica. Em seguida, os estudantes assistiram ao filme na íntegra, ao que, então, se procedeu uma discussão, que foi totalmente áudio gravada, especificando a relação entre pais e filhos, professor e estudantes, expectativas de uma carreira profissional, círculos de amizades, a cultura local, a mina como única fonte de renda, o ensino de Ciências, bolsas de estudos, feira de ciências e o lançamento do foguete Sputnik como fator motivador de pesquisa científica.

Decorridos 14 dias da realização da atividade, propusemos novamente o mesmo questionário aos estudantes, a fim de analisar as percepções antes e depois do filme. É imprescindível ressaltar que o foco para a realização deste artigo foi somente a análise da discussão realizada após os alunos assistirem ao filme.

\section{TRANSCRIÇÕES DAS FALAS}

A discussão realizada após o término do filme, ou seja, as falas dos estudantes, da professora e das acadêmicas do PIBID, foram gravadas e transcritas literalmente, reproduzindo fielmente as falas realizadas no momento da atividade, 
sendo considerados os aspectos fundamentais, como as pausas e prolongamento de vogal, no momento do registro (THOMPSON, 1992).

A autorização para uso de som e imagem é fornecido pelos responsáveis dos estudantes no ato de matrícula. A fim de padronizar, para que pudessem ser facilmente interpretadas, utilizamos as normas de transcrição que são detalhadas no Quadro 2 a seguir, no qual se apresenta o significado de cada convenção empregada. Após a transcrição das falas, seguimos para a análise delas.

Quadro 2: Principais Sinais Acordados em uma Transcrição no Brasil

\begin{tabular}{c|c}
\hline Sinais & Normas Acordadas em Transcrição de Dados \\
\hline & Para indicar qualquer tipo de pausa \\
\hline & Para indicar hipótese do que se ouviu \\
\hline & Para inserção de comentários do pesquisador \\
\hline & Para indicar prolongamento de vogal ou consoante. Ex.: "éh::" \\
& Para silabação de palavras. Ex.: "di-la-ta-ção" \\
\hline
\end{tabular}

Fonte: Estudo comparado dos padrões de concordância em variedades brasileiras, europeias e africanas, coordenado por Silvia Rodrigues Vieira e Maria Antónia Ramos Coelho da Mota².

\section{RESULTADOS E DISCUSSÕES}

A atividade desenvolvida busca enfatizar a importância da intervenção do professor nas discussões dos alunos e seus objetivos, podendo incentivá-los a participar da discussão ou reprimi-los, dependendo da maneira como ele medeia o debate. Busca desenvolver uma linguagem para o discurso dentro de sala de aula, ou seja, analisar como diferentes formas de abordagem se associam às intenções do professor em várias fases no desenvolvimento da aula. A partir dessa metodologia, de Mortimer e Scoot (2002), foram analisadas as transcrições da discussão do filme: "O Céu de Outubro". Toda a discussão foi mediada pela professora para manter o foco dos estudantes nos temas abordados, nos quais todas as respostas foram consideradas.

\section{TRANSCRIÇÃO DA AULA: "DISCUTINDO O FILME 'O CÉU DE OUTUBRO""}

Nas transcrições das falas foram utilizadas codificações, sendo P (P1 até P3) para as integrantes do PIBID (acadêmicas participantes da discussão), S para a professora supervisora e regente da turma, e E para os estudantes, sendo En quando vários estudantes falam ao mesmo tempo.

\section{Episódio 1}

P1: Então vamos falar discutir um pouco mais o contexto social político e econômico... qual é o contexto que o filme se passa?

E1: A guerra fria?

E2: No tempo da guerra fria... 
P1: Isso no começo... no início do filme... o que foi lançado?

En: O Sputnik...

P1: Sim... e o Sputnik era::? Foi o::?

En: Éh:: ((pensativos))

P1: O que antecedeu então ah:: a guerra fria... e o que os moradores da cidade pensavam quando foi lançado?

E4: Que era espionagem...

P1: Que era a espionagem... então vocês acham então que uma guerra pode motivar pesquisas de iniciação cientifica?

En: Sim...

E1: Lógico...

P2: Vocês conhecem algum outro fator que partiu da guerra?

E5: Sim...

P2: Qual?

E2: GPS...

P2: GPS...

En: ((muitos estudantes estavam discutindo entre eles nesse momento))

E1: Não seria mais pela necessidade ((não compreendemos))?

P2: Necessidade? Silêncio pessoal... vamos prestar atenção aqui...

E1: Se a gente for ver antigamente no Brasil quando eles começaram fazer as vacinas e teve aquela revolta das vacinas as pessoas não sabiam o que eram e pra que serviam... só tipo eles foram contra o que eles tinham para curar...

P2: Ahamm... muitas tecnologias surgem né e as pessoas elas não têm informação suficiente pra saber o quanto que aquilo é importante né ou não... até que ponto nos afetam né... que foi o problema que não foi um problema né... eh:: o satélite trouxe assim foi o início de uma nova era né... início de uma nova tecnologia... só que muitos não têm conhecimento e acabam tendo outros olhos que nem você falou o motiv/ as vacinas trouxe uma revolta... lógico foi uma falta de informação mais alguma observação...

Nesse episódio, a discussão se iniciou com a professora e as integrantes do PIBID convidando os estudantes a participarem do debate e oferecerem as suas ideias sobre os aspectos sociais e políticos abordados no filme, engajando-os a identificarem a época de ocorrência do filme e sobre os acontecimentos históricos do filme.

O foco de ensino e as intenções do professor são apresentados a seguir, no Quadro 3: 
Quadro 3: Foco do Ensino - Intenção do Professor no Episódio 1

\begin{tabular}{c|c|c}
\hline Episódio & Intenção do Professor & Foco \\
\hline \multirow{3}{*}{1} & $\begin{array}{c}\text { - Explorando a visão dos } \\
\text { estudantes }\end{array}$ & $\begin{array}{c}\text {-Engajar os estudantes referentemente } \\
\text { ao contexto social e político; } \\
\end{array}$ \\
& $\begin{array}{c}\text { - Explorar as ideias dos estudantes sobre } \\
\text { a guerra, lançamento do Sputnik e como } \\
\text { esses fatores podem motivar pesquisas } \\
\text { científicas. }\end{array}$ \\
\hline
\end{tabular}

Fonte: Autoria Própria (2017).

De acordo com Cipolini (2008), o filme é utilizado como um instrumento didático quando se refere a acontecimentos históricos que retratam conteúdos, como foi abordado no lançamento do Sputnik, contextualizando com outras situações relatadas pelos estudantes, relacionadas com pesquisas científicas, que puderam e podem servir como fator motivador para a área científica. Além disso, o filme pode ser utilizado como motivador na discussão de temáticas que abordam o contexto social e político, que também são retratados no filme.

Os episódios 1, 2, 3 e 4 são relacionados com a intenção do professor no decorrer da atividade: explorar a visão dos estudantes. Ressaltando que, de acordo com Cunha (2009), a percepção é uma elaboração criada pelo sujeito a partir daquilo que é sentido, detectado por meio de memórias e de vivências de cada pessoa.

\section{Episódio 2}

P2: O contexto econômico? O que que vocês observaram?

E1: Que a mina trazia muito dinheiro pra cidade...

E2: A mina era o sustento da cidade...

E1: E eles tinham medo que a mina parasse de funcionar... eles perderiam muito dinheiro...

P2: E qual era a influência do contexto familiar com o contexto econômico?

E3: O pai dele era o chefe de mina...

P2: E o que que isso influenciava?

E4: Fazia todos trabalharem na mina...

P3: E será que isso era só econômico... assim era só por questão:: pelo dinheiro que a mina trazia pra cidade que todos que cresciam na cidade deveriam trabalhar na mina... isso era só econômico? Ou tinha alguma outra coisa?

E1: Não... porque o pai obrigava...

P2: Mas por que que o pai obrigava? Será que era só preocupação com o dinheiro com o sustento?

E2: Não... é que quando o pai tem uma empresa de certo modo... ou alguma outra coisa... ele sempre vai querer que o filho siga sempre o mesmo caminho...

P1: Vocês acham que os pais que determinam o futuro dos filhos?

En: ((não compreendemos))

P1: Eles podem influenciar? 
En: Po-de

P1: Mas cabe a cada um...

En: ((não compreendemos))

E2: Ele foi influenciado de qualquer forma porque ele trabalhou um tempo na mina e só voltou lá porque tinha descoberto que o foguete não tinha causado o incêndio...

P2: Vocês perceberam o que o nosso colega falou? Teve um momento que o contexto familiar veio em primeiro lugar... ele teve que deixar um pouco de lado o sonho dele e trabalhar com o pai dele... foi mais alto... mesmo ele não querendo isso pra ele teve um momento que ele teve que deixar de lado... não agora vem minha família em primeiro lugar...

E6: Ele teve que ir porque o pai dele tinha se machucado...

P2: Sim tinha se machucado...

E2: E ele tinha que trazer dinheiro pra casa...

P1: E naquela cidade como a mina era a fonte de renda das pessoas... éh:: isso mostra como a questão cultural tá envolvida... todos na cidade... qual era o destino das pessoas?

En: Ir pra mina...

P1: Isso já estava quase determinado naquela cidade...

P2: Mas isso só tava determinado pela família?

En: Não não...

P2: Quem outra pessoa também que falou que... ah:: que não era pra alimentar os sonhos né? Que o futuro já estava destinado...

E1: O diretor...

P2: Então era muito forte essa tradição... essa cultura porque até na escola traziam isso... traziam isso para os alunos...

E3: Eu acho que o não era muito o diretor... éh:: naquela área ali ele sempre via os alunos indo pra mina... só alguns se destacavam por causa da bolsa de esportes...

P2: E quem que iam pras universidades?

En: Só os jogadores...

P2: Isso é uma cultura dos Estados Unidos... pessoas que:: uma cultura deles de trabalharem desde cedo... é o esporte:: é o esporte que determina o futuro deles que vão até as universidades e isso acontece até hoje vocês viram até nos jogos olímpicos né... (E1: no Brasil) quem foram os ganhadores né quem se destacou? Mas isso gente isso acontece porque é uma cultura deles... isso é uma cultura deles... diferente da nossa realidade né...

O foco de ensino e as intenções do professor são apresentados no Quadro 4 abaixo: 
Quadro 4: Foco do Ensino - Intenção do Professor no Episódio 2

\begin{tabular}{c|c|c}
\hline Episódio & Intenção do Professor & Foco \\
\hline \multirow{2}{*}{2} & $\begin{array}{c}\text { - Explorando a visão dos } \\
\text { estudantes }\end{array}$ & $\begin{array}{c}\text { - Questionar os estudantes sobre os } \\
\text { contextos econômico, familiar e cultural } \\
\text { apresentados no filme; }\end{array}$ \\
& $\begin{array}{c}\text { - Explorar as ideias dos estudantes sobre } \\
\text { o trabalho na mina, relação entre pai e } \\
\text { filho e sobre a influência da cultura na } \\
\end{array}$ & vida das pessoas. \\
\hline
\end{tabular}

Fonte: Autoria Própria (2017).

No Episódio 2, a professora e as acadêmicas questionam os estudantes sobre a forma como os aspectos econômicos, culturais e familiares estão apresentados no filme, e a maneira como esses fatores podem influenciar na vida das pessoas. Além disso, é discutido sobre a relação entre pai e filho e o trabalho na mina como única fonte de renda da cidade.

No episódio, é visível o significado cultural do filme no contexto em que ele foi produzido, pois retrata a tradição dos Estados Unidos em relação às bolsas de estudo para estudantes com destaque nos esportes e sobre o trabalho na mina, que era a cultura da população da cidade. Dessa forma, Duarte (2002) aponta que algumas das percepções que temos hoje de ciência podem estar ligadas ao contato que tivemos com imagens cinematográficas, destacando os aspectos históricos, sociais e culturais como fatores preponderantes na produção de filmes.

\section{Episódio 3}

P2: Mas o que que mais que:: que o Homer fez então pra conseguir essa bolsa de estudos?

E1: Entra pra feira de ciências...

P2: E teve alguém que influenciou... teve alguém que estava do lado dele?

E1: A professora...

E3: O senhor Smith...

P2: Quem?

E3: O senhor Smith lá que montou uma bike lá ((não compreendemos))

P2: E o Homer?

E3: Homer Simpsons...

P2: Gente sem brincadeira:: e o que que vocês viram no Homer desde o começo da trajetória dele até chegar à bolsa de estudos?

E1: Persistente...

En: Ele não desistia fácil...

P2: E qual era a característica dele no começo?

E2: No começo ele queria jogar futebol...

P2: Por quê?

E2: Era uma maneira mais fácil de chegar na faculdade... 
E1: Porque seria uma forma de impressionar o pai dele...

E2: Mas se ele quisesse impressionar o pai dele ele teria ficado na mina ((não compreendemos))...

En: ((muitos estudantes estavam discutindo o assunto entre eles nesse momento))

P2: Quem motivou o Homer a ir atrás de uma bolsa de estudos? Qual foi o fator?

E2: Eu acho que foi por causa do irmão dele que jogava...

P2: Mas não teve outra coisa que também motivou ele?

P1: Do nada assim?

E1: As pessoas que foram lá ver eles soltarem o foguete... talvez... que eles estavam começando a querer desistir a hora que eles chegaram para soltar o foguete e as pessoas estavam lá... foi um motivo a mais para eles mostrar que eles conseguiam...

P2: Mais qual foi o motivo principal? Que fez ele pensar assim... ah:: eu posso...

P1: Do nada? Vou lança um foguete... vou montar um foguete?

P2: O que fez?

E1: Foi o satélite...

E2: Sputnik...

P2: Foi o Sputnik... ele observou no céu o Sputnik... então isso fez... isso motivou ele a ir atrás do sonho dele... aí partiu a ideia do foguete... não foi assim... acordei e pá:: hoje eu vou fazer um foguete...

En: ((não compreendemos))

P2: Pode fala...

E1: Mas que nem que ele estava escrevendo a carta... pro:: pro:: (pro herói dele) pro cientista lá... aí eles contava que todo mundo tava apoiando eles... mais ele mentiu...

P1: Pela vergonha né que... pela cidade... e a maioria do pessoal não apoiarem ele... mais eles na primeira derrota no primeiro fracasso eles desistiram?

En: Não...

P1: Então isso é uma característica de quem quer o sucesso... se na primeira derrota a gente desistir a gente nunca consegue nossos sonhos se realizar... nossos sonhos... Então essa escolarização... ela remete a um retorno financeiro? Você acha que o estudo ele vai remeter a um futuro? Vai ter um retorno financeiro?

E: Vai..

P2: Até como? Por quê?

En: ((não compreendemos))

P1: No filme quais:: qual foi o futuro de Homer e os amigos?

Página | 159

En: ((não compreendemos)) 
E2: Virou Cientista...

E3: Todos ganharam uma bolsa da faculdade...

P1: Os outros dois como não tinham... os dois amigos... como não tinham mais éh:: aquele dom... eles foram para outros ramos né... um era bancário outro se torno dono de uma seguradora e Homer então foi... é um engenheiro da NASA...

En: Cientista...

P1: Sim... engenheiro químico...

E3: Engenheiro químico...

O foco de ensino e as intenções do professor são apresentados no Quadro 5:

Quadro 5: Foco do Ensino - Intenção do Professor no Episódio 3

\begin{tabular}{c|c|c}
\hline Episódio & Intenção do Professor & Foco \\
\hline \multirow{3}{*}{3} & $\begin{array}{c}\text { - Explorando a visão dos } \\
\text { estudantes }\end{array}$ & $\begin{array}{c}\text { - Perguntar aos estudantes a respeito de } \\
\text { bolsas de estudos, feira de ciências e } \\
\text { futuro profissional; }\end{array}$ \\
& $\begin{array}{c}\text { - Engajar as ideias relacionadas à postura } \\
\text { e influência da professora, persistência } \\
\text { como característica essencial do cientista } \\
\end{array}$ & $\begin{array}{c}\text { e de um futuro promissor; } \\
\text { - Lançamento Sputnik como ponto de } \\
\text { partida para o projeto da feira de } \\
\text { ciências. }\end{array}$ \\
\hline
\end{tabular}

Fonte: Autoria Própria (2017).

Bolsas de estudo e feira de ciências são temas do Episódio 3, no qual a professora e as acadêmicas exploram as ideias dos estudantes sobre o objetivo de Homer e os amigos entrarem para a feira de ciências do colégio, na tentativa de conseguirem bolsas de estudo, pois a escolarização pode remeter ao sucesso profissional e financeiro e a persistência é uma característica essencial do cientista.

De acordo com Cipolini (2008), observa-se, nesse episódio, que o filme pode ser utilizado como motivador de debates sobre temas políticos, históricos, culturais e econômicos, pois relaciona a participação dos estudantes na feira de ciências, a persistência com a carreira profissional e a forma como acontecimentos marcantes na história, por exemplo o lançamento do Sputnik, podem servir como ponto de partida para a produção do filme e motivação dos estudantes na elaboração de projetos para a feira de ciências.

\section{Episódio 4}

P1: Então uma feira de ciências ela pode ser refletida de aspectos sociais da socie/ que está acontecendo na sociedade... no caso ali que o motivador foi o lançamento do satélite e aqui agora... como vocês vão bolar o projeto de vocês? Como que vocês vão fazer para a feira de ciências? Vocês não acham que tá muito sem utilidade vocês... ah:: vou pesquisar na internet e achar um projeto pronto e vou fazer...

E2: Tipo isso...

P2: Isso acrescenta? 
S: Alguém falou aqui o vulcão...

P3: Será que esse é o real objetivo da feira de ciências?

E3: E quem falou isso... ((risos))

En: ((não compreendemos)) ((risos)) ((muitos estudantes estavam discutindo $\mathrm{o}$ assunto entre eles nesse momento))

P1: Qual que é o objetivo de ir pra feira de ciências... reproduzir algo que já está pronto?

En: Não...

P1: Algum talento?

P1: Ou a parte de uma resolução de algum problema...

E1: Mais eu acho que agora tipo... por exemplo tá muito difícil você criar algo novo mais...

P2: Será? Vocês conc/...

S: Mais eles criaram algo novo?

E1: Não...

E2: Pra eles sim...

S: Pra eles sim... mais era algo novo... totalmente novo?

E2: Não...

P2: Qual foi o primeiro foguete? Falou no começo do filme? Quem que...

E3: Foi antes de Cristo ainda...

E3: China...

P2: Quantos anos antes?

E3: Mil anos...

P2: Mil anos antes de Cristo... para os chineses era algo novo?

En: Não...

P1: Vocês só precisam se destacar naquilo que vocês fazem... não importa se já foi feito se a outra pessoa fez... você tem que se destacar naquilo que vocês fa/...

S: Diferenciar...

P1: Diferenciar...

P2: Às vezes melhorar o que já tem né... tem algo novo mais você pode melhorar...

P1: Ou fazer pelo um método diferente...

S: É ou apresentar outra percepção daquilo...

P1: Alternativa...

P1: Então fica pra vocês pensarem porque a feira de ciências não é pra ser feito assim pra ganhar pontos na média... é pra vocês pensarem em algo que vai ser útil pra sociedade mesmo... 
P2: Mais algum comentário... alguma observação... então tá bom pessoal hoje a atividade foi essa... espero que vocês tenham gostado tenham aproveitado e fica aí a ideia pra vocês pensarem no projeto de vocês pra feira... muito obrigada...

En: ((palmas))

O foco de ensino e as intenções do professor estão apresentados no Quadro 6:

Quadro 6: Foco do Ensino - Intenção do Professor no Episódio 4

\begin{tabular}{c|c|c}
\hline Episódio & Intenção do Professor & Foco \\
\hline \multirow{3}{*}{4} & - Explorando a visão dos & - Relacionar a feira de ciências retratada \\
& estudantes & no filme com a feira do Colégio; \\
& & $\begin{array}{c}\text { - Abordar os objetivos da construção de } \\
\text { trabalhos para uma feira de ciências. }\end{array}$ \\
\hline
\end{tabular}

Fonte: Autoria Própria (2017).

No Episódio 4, a professora e as acadêmicas relacionam a feira de ciências retratada no filme com a feira realizada no colégio. São exploradas as percepções que os estudantes possuem sobre feiras de ciências, sobre os objetivos de uma feira dessas e como se deve proceder na pesquisa científica e na construção dos trabalhos. Ao finalizar, foi ressaltada a importância dessas práticas não só para ganhar pontos na vida escolar, mas também, na vida em sociedade.

Dessa forma, de acordo com Cipolini (2010), o filme utilizado pode ser considerado instrumento auxiliador de um objeto do conhecimento, pois ilustra a realidade de uma feira de ciências escolar, a fim de buscar o aperfeiçoamento do processo educativo, sustentando os debates em sala de aula e como forma de reconstrução da realidade.

\section{CONCLUSÃO}

Mortimer e Scott (2002) afirmam que a abordagem de uma didática mediante uso de filme em sala de aula depende das intenções do professor, sendo desenvolvida em várias fases da aula. Dessa forma, na análise descrita neste artigo, podemos observar que a forma como a professora e as acadêmicas fazem as intervenções nas discussões com os estudantes pode instigar ou coibir a participação deles.

Assim, percebe-se que a professora e as acadêmicas pibidianas, na discussão do filme "O Céu de Outubro", tiveram as suas intenções bem direcionadas em explorar as visões dos estudantes e os focos eram baseados nas visões que os estudantes possuíam em relação ao contexto de cada episódio.

Com este trabalho foi possível constatar que a utilização do filme como uma ferramenta de ensino pode auxiliar o professor na exploração de ideias que os estudantes possuem sobre Ciências, isso em seus aspectos sociais, culturais, políticos e econômicos e também sobre a finalidade das feiras de ciências nas escolas. Essa atividade proporcionou aos participantes uma maior percepção de ciência, abrangendo os contextos já citados.

É, portanto, de grande relevância utilizar metodologias diferenciadas para o aperfeiçoamento do processo de ensino-aprendizagem, como no caso o filme 
trabalhado, ou outras ferramentas metodológicas, que podem relacionar os conteúdos abordados com a realidade dos estudantes. 


\title{
Analysis of perceptions of high school students about the film: "The October Sky"
}

\begin{abstract}
This article presents an activity carried out with students of the 3rd Year of High School on the film "The October Sky" This film portrays the commitment of students from a small town who are dedicated to building a rocket in order to be selected for the science fair. In the activity, the students critically analyze aspects / contexts addressed in the film plot. The objective of this work was to propose to the students a critical analysis of the familiar, political, historical, social and scientific activity related to the science fair presented in the film, using the proposal presented in the article by Eduardo Fleury Mortimer and Phil Scott, which proposes a tool to analyzing the interventions and the intentions in the classroom teacher's discourse. The method of analysis provided subsidy to conclude that the proper course of discussion of the film depends on the interventions of the teacher, which mediates the discourse to the desired intention and focus, exploring students' views on the contexts pointed out in the film.
\end{abstract}

KEY-WORDS: Chemistry Teaching. Discursive Activity. Perceptions. Interventions. Film. Science Fair. 


\section{NOTAS}

1 MORTIMER, E. F.; SCOTT, P. Investigações em Ensino de Ciências, v. 7, n. 3, p. 283-306, 2002.

2 Disponível em:

$<$ http://www.concordancia.letras.ufrj.br/index.php?option=com_content\&view= article\&id=52\&ltemid=58>. Acesso em: 23 fev. 2017.

\section{REFERÊNCIAS}

ALENCAR, S. E. P. O cinema na sala de aula: uma aprendizagem dialógica da disciplina História. Dissertação (Mestrado). Fac. de Educação. Univ. Federal do Ceará. Fortaleza/CE. 2007. Disponível em: <http://www.pucrs.br/famat/viali/tic_ literatura/filmes/C13.pdf>. Acesso em: 2 abr. 2017.

AGUDO, S. E.; OTOFUJI, M. Museu Dinâmico Interdisciplinar. Disponível em: $<$ https://museudinamicointerdisciplinar.wordpress.com/2012/08/17/resenhado-filme-ceu-de-outubro/>. Acesso em: 15 mar. 2017.

ARAÚJO, S. A. Possibilidades pedagógicas do cinema em sala de aula. Revista Espaço Acadêmico, n. 79, dez. 2007.

CIPOLINI, A. Não é fita, é fato: tensões entre instrumento e objeto - um estudo sobre a utilização do cinema na educação. Dissertação (Mestrado). Faculdade de Educação. Universidade de São Paulo, São Paulo, 2008.

COELHO, R. M. F.; VIANA, M. C. V. A utilização de filmes em sala de aula: um breve estudo no Instituto de Ciências Exatas e Biológicas da UFOP. Revista da Educação Matemática da UFOP, v. 1, 2011 - X Semana da Matemática e II Semana da Estatística, 2010.

CUNHA, M. B. A percepção de Ciência e Tecnologia dos estudantes de ensino médio e a divulgação científica. 2009. Tese (Doutorado). Faculdade de Educação. Universidade de São Paulo, São Paulo, 2010. Disponível em: <http://www.teses.usp.br/teses/disponiveis/48/48134/tde-02032010091909/pt-br.php>. Acesso em: 4 mai. 2017.

DUARTE, R. Cinema \& Educação. Belo Horizonte, MG: Autêntica, 2002.

KLIEMANN, C. R. M. et al. O filme "O Céu de Outubro" e a percepção dos estudantes sobre o ensino de Ciências. V simpósio Nacional de Educação e XXVI 
MORTIMER, E. F.; SCOTT, P. Atividade discursiva nas salas de aula de Ciências: uma ferramenta sociocultural para analisar e planejar o ensino. Investigações em Ensino de Ciências, v. 7, n. 3, p. 283-306, 2002.

SANTAELLA, L. A percepção: uma teoria semiótica. 2. ed. São Paulo: Experimento, 1998.

SASSERON, L. H.; CARVALHO, A. M. P. Alfabetização científica: uma revisão bibliográfica. Investigações em Ensino de Ciências, v. 16, n. 1, p. 59-77, 2011. Disponível em: <http://www.if.ufrgs.br/ienci/artigos/Artigo_ ID254/v16_n1_a2011.pdf >. Acesso em: 5 mar. 2017.

THOMPSON, P. A voz do passado: história real. 3. ed. Trad. Lólio Lourenço de Oliveira. Rio de Janeiro: Paz e Terra, 1992.

VIANA, M. C. V. Perfeccionamiento del currículo para la formación de profesores de Matemática em la UFOP. Tese (Doutorado). ICCP-Cuba. 2002.

Recebido: 30 jul. 2017

Aprovado: $18 \mathrm{dez} .2017$

DOI: $10.3895 /$ actio.v3n1.6847

Como citar:

LUDVIG, et al. Análise das percepções de estudantes do ensino médio sobre o filme: "O Céu de Outubro".

ACTIO, Curitiba, v. 3, n. 1, p. 148-166, jan./abr. 2018. Disponível em: <https://periodicos.utfpr.edu.br/actio>

Acesso em: XXX

Correspondência:

Daiane Thais Ludvig

Rua Nossa Senhora da Luz, n. 170, Jardim Santa Maria, Toledo, Paraná, Brasil.

Direito autoral: Este artigo está licenciado sob os termos da Licença Creative Commons-Atribuição 4.0

Internacional.

\section{(c) (1)}

